\title{
Com Um Toque de Criação': a mediação pedagógica na formação de leitores e escritores na Educação de Jovens e Adultos
}

\author{
With A Touch of Creation: The pedagogical mediation on the \\ formation of readers and writers in Youth and Adult Education
}

https://doi.org/10.34112/2317-0972a2020v38n80p45-63

Maria dos Anjos Lopes Viella ${ }^{2}$

Marizete Bortolanza Spessatto ${ }^{3}$

RESUMO: Este texto trata da mediação do professor em experiências de formação de leitores e escritores na Educação de Jovens e Adultos. As atividades relatadas foram desenvolvidas com turmas do Programa Nacional de Integração da Educação Profissional Técnica de Nível Médio na modalidade de Jovens e Adultos - PROEJA. A partir desse trabalho, foi possível a organização de cinco livros, dois deles publicados pelo IFSC e os demais produzidos artesanalmente. Ao longo deste texto, são submetidas à análise quatro produções relacionadas a essa experiência. Elas se constituem em exemplares vivos de alternativas didáticas que podem ser colocadas em prática por outros docentes e estudantes que têm histórias para ler e para contar, contanto que sejam abertas possibilidades para tal, o que é um papel, mesmo que tardio, da Educação de Jovens e Adultos.

PALAVRAS-ChAVE: Leitura; escrita; mediação pedagógica.

ABSTRACT: This text is about the mediation of the professor on teaching experiences of readers and writers in Youth and Adult Education. The reported activities were elaborated along with classes of the National Higher Secondary Technical Professional Education

1. Um Toque de Criação é o título de um dos livros analisados neste artigo, organizado pelas professoras Gevaerd e Kawano (2006), publicado como produção independente.

2. Instituto Federal de Educação, Ciência e Tecnologia de Santa Catarina, Florianópolis, SC, Brasil.

3. Instituto Federal de Educação, Ciência e Tecnologia de Santa Catarina, Florianópolis, SC, Brasil. 
Com Um Toque de Criação: a mediação pedagógica na formação de leitores e...

Program in the Youth and Adult category - PROEJA. This work made possible the creation of five books, of which two were published by the IFSC and the others were handcrafted. Throughout this text, four productions of this experience are going under analysis. Together they are living pieces of didactic alternatives that can be put into practice by other teachers and students that have stories to read and to tell, provided that possibilities are opened to them, which is a role, even if late, of the Youth and Adult Education.

KEYWORDS: Reading; writing; pedagogical mediation.

\section{INTRODUÇÃO}

Pensar a formação de leitores articulada ao exercício da escrita é um desafio que envolve todos os níveis e modalidades de ensino. E se o trabalho com a leitura e a escrita é fundamental para o ensino regular, quanto mais para as classes de jovens e adultos, cujos sujeitos foram privados desses conhecimentos na dita "idade certa". Este texto contempla experiências de mediação docente que impulsionaram não apenas a conquista dos conhecimentos escolares, mas também a vida dos sujeitos envolvidos. Os tópicos a seguir, que compõem esta produção, referem-se a práticas realizadas com alunos do Programa Nacional de Integração da Educação Profissional Técnica de Nível Médio na modalidade de Jovens e Adultos (PROEJA), em aulas de Português, no Instituto Federal de Santa Catarina (IFSC), Campus Florianópolis, desenvolvidas durante os anos de 2005 a 2010. Após a contextualização do cenário das produções em análise, serão focalizados, pela ordem cronológica de sua publicação, três livros resultantes dessa prática e cujos títulos dão nome às seções seguintes.

\section{O CONTEXTO De PRoduÇão: as Ofertas Proeja nos Institutos Federais}

As experiências analisadas neste artigo resultam de trabalhos desenvolvidos com alunos do Programa Nacional de Integração da Educação Profissional com a Educação Básica na Modalidade de Educação de Jovens e Adultos. Este programa foi criado pelo decreto n. ${ }^{\circ} 5.478 / 2005$ como formação técnica de nível médio e, posteriormente, foi reformulado, incluindo toda a Educação Básica e as instituições de ensino estadual, municipal ou particular, além da rede federal, na qual a oferta se tornou obrigatória.

Mesmo com os documentos legais impulsionando as propostas de cursos na modalidade de Educação de Jovens e Adultos, os números reais de oferta estão longe de alcançar os dez por cento do total das ofertas de vagas, conforme previsto 
legalmente. A Educação de Jovens e Adultos nessa instituição começou a ser ofertada em 2004, no campus Florianópolis, por um grupo de professores da área de Formação Geral que implantou o Ensino Médio para Jovens e Adultos (EMJA).

Em virtude do Decreto n. ${ }^{\circ}$ 5.478/2005 (BRASIL, 2005), a EJA na instituição passou a ser ofertada por meio do PROEJA, no primeiro semestre de 2006. Entretanto, embora esteja previsto legalmente que $10 \%$ das vagas de ingresso das instituições da Rede Federal sejam preenchidas nesses cursos, os números, até o presente momento, alcançam pouco mais de $4 \%$. Outro problema destacado por Ramos e Brezinski (2014) é que, embora faça parte das ações de expansão da educação profissional, a adoção do Proeja não foi acompanhada pela contratação de novos professores, nem pela preparação dos existentes para atuarem com esse público diferenciado. Dessa forma, houve resistência dos docentes a lecionar nesses cursos ou problemas de adequação às especificidades dos alunos.

Haddad (2007 apud RAMOS; BREZINSKI, 2014) chama a atenção para a reprodução de práticas curriculares, metodológicas e pedagógicas aplicadas às crianças e aos adolescentes sendo usadas nas aulas da EJA. É preciso, destaca Oliveira (1999), definir a especificidade de jovens e adultos e refletir sobre a condição de não-crianças; a condição de excluídos da escola; e a condição de membros de determinados grupos sociais e culturais.

São questões como essas que impulsionam a partilha dessas experiências que visam, além de assegurar o desenvolvimento da leitura e da escrita para os sujeitos da Educação de Jovens e Adultos, ampliar sua autonomia, nesse processo. Experiências que mostram os resultados a que esse trabalho pode levar, quando movido pela mediação e pelo comprometimento docentes.

Cada um desses livros é resultado do trabalho de mediação nas aulas de Língua Portuguesa - um deles em parceria com a disciplina de Geografia, Um toque de criação, 2006. Para além de estudar aspectos como tipologias textuais, ortografia e concordância, por exemplo, os alunos foram chamados a assumir o protagonismo e a usar os conhecimentos linguísticos para contar suas próprias histórias: Proeja - o aluno, 2009; O vento que vem de longe, 2006. Eles também foram levados a construir coletivamente textos narrativos, percorrendo contos de grandes nomes da literatura, como Machado de Assis, e do folclore, como Franklin Cascaes (Vivendo e aprendendo com a turma 123, 2008). As seções que seguem têm como títulos os nomes das produções aqui em análise. 
UM TOQUE DE CRIAÇÃO

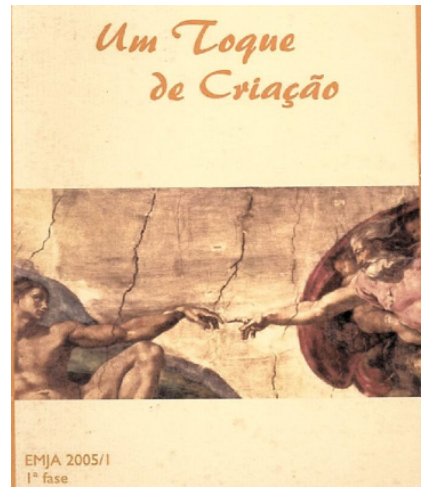

\begin{abstract}
"Não sou de criar raízes. Não gosto de cercas, portões, grades, muros altos, 'não entre', 'proibido'... Quero ter muitos lugares, principalmente no coração de todas as pessoas que conheço e ainda vou conhecer" (texto de Emirame Demaria Silva, publicado em GEVAERD; KAWANO, 2006, p. 38).
\end{abstract}

A produção que inspira o título deste artigo contém textos produzidos pelos 22 sujeitos que constituíam a turma 2005/1, da primeira fase do Ensino Médio para Jovens e Adultos (EMJA) e foi publicada em junho de 2006. Na apresentação, as organizadoras trazem um pouco do perfil da turma: "Idades que variam de 22 a 59 anos. Grande parte deles está afastada dos bancos escolares há mais tempo, mais de trinta anos, até" (GEVAERD; KAWANO, 2006, p. 04). O que os caracteriza, segundo as autoras, é "a vontade de estudar e o valor que dão ao estudo, afinal, são pessoas que, por variados motivos, alheios a sua vontade, foram afastados da escola” (p. 04).

As características apontadas pelas professoras do Proeja que atuaram como organizadoras da obra revelam um perfil de estudantes que em muito se assemelha com o perfil nacional dos sujeitos que retornam aos bancos escolares, como indicam Faria e Assis (2014), que destacam que, da heterogeneidade característica do público EJA, "o grande desafio para o docente é aprender a trabalhar com sujeitos que não concluíram o ensino médio, que têm idades diferenciadas e, acima de tudo, são jovens e adultos trabalhadores" (FARIA; ASSIS, 2014, p. 126).

A primeira parte do livro Um toque de criação é composta por textos produzidos pelos alunos nas aulas de Geografia, nos momentos em que refletiam com a professora sobre o lugar onde viviam, trabalhavam, estudavam. Já a segunda parte contém produções resultantes de estudos do texto narrativo, explorando a fala do narrador e do personagem, em discurso direto e indireto. Os alunos foram incentivados a produzir um texto narrando um episódio de infância. Sobre o lugar, há 22 textos produzidos e sobre a infância, 19 textos, resultando numa obra com 41 produções, 
em um total de 84 páginas. Para os propósitos deste artigo, serão tomados como objeto de estudo apenas os textos da primeira parte.

"Achamos que esses textos não deveriam ficar restritos a nós, por isso os reunimos aqui e os compartilhamos com você" (GEVAERD; KAWANO, 2006, p.3), informam as professoras-autoras, no final da apresentação da obra. A proposta deste artigo é dar mais visibilidade à produção, feita de forma amadora e sem recursos, enfatizar a mediação pedagógica, que estimulou a autoria dos alunos e se materializou nas obras produzidas, além de revelar a importância das experiências interdisciplinares.

Ilustrações feitas pelos próprios alunos, destacando como o formato das atividades realizadas traziam reflexões sobre os conteúdos das disciplinas de Geografia e Português e dialogavam com a vida dos estudantes: "Percebemos que tínhamos um mapa em nossa sala e tínhamos colegas do Rio Grande do Sul, Maranhão, Ceará, Tocantins, Bahia, Rio de Janeiro, do interior de Santa Catarina e, principalmente de Florianópolis", contam os alunos Andréa Fernandes e Maurício Felix (GEVAERD; KAWANO, 2006, p. 26).

As histórias sobre o lugar vão revelando as andanças das famílias nas buscas pelo emprego, principalmente nas lavouras; enfim, o lugar do trabalho aparece repetidas vezes. Oliveira (1999) destaca, em relação ao perfil da maioria dos estudantes da EJA: "Ele é geralmente o migrante que chega às grandes metrópoles proveniente de áreas rurais empobrecidas, filho de trabalhadores rurais não qualificados e com baixo nível de instrução escolar" (OLIVEIRA, 1999, p. 59). A história contada pelo aluno Fausto Souza Reis ilustra bem a questão: "Faz muito tempo que eu saí do meu lugar. Saí de São Luiz em 1997 para estudar e trabalhar. Sempre estudei e trabalhei. Hoje era para estar formado. Houve contratempos, mas não desisti. O meu sonho é me formar em Administração e voltar para o meu lugar" (GEVAERD; KAWANO, 2006, p. 44).

As produções também trouxeram à tona a imagem da sala de aula como espaço de interações significativas de vivência do humano. "No segundo dia de aula, eu escolhi o lugarzinho predileto, como se a carteira fosse minha, não me dando assim oportunidade de fazer novas amizades", conta Andréa Dias. Ela continua o seu depoimento, revelando que, com a mediação dos professores, passou a se relacionar com outros colegas, sem ficar presa ao mesmo lugar na sala. "Agora eu entendo como foi bom sair do lugar predileto. Fiz novas amizades com pessoas com quem nunca imaginava conversar" (GEVAERD; KAWANO, 2006, p. 34).

$O$ trabalho e a escola se entrelaçam em alguns textos, mas não de maneira conciliatória. Essas histórias narram a entrada tardia na escola ou também relatam um 
Com Um Toque de Criação: a mediação pedagógica na formação de leitores e...

processo com muitas paradas, como conta Adão Rosa: "Então eu comecei a estudar [com nove anos]. Estudei um ano e meio e a minha mãe tornou a me tirar de novo do colégio. Ela dizia que eu tinha que ajudar ela a trabalhar na roça. [...] Eu nunca mais estudei. Só voltei a estudar no ano passado" (GEVAERD; KAWANO, 2006, p. 72).

Um toque de criação também se caracteriza como uma obra que assegura o estímulo àqueles que estão fora da escola e têm o desejo de a ela retornar. Mariléia da Rosa destaca o entusiasmo que sentiu ao encontrar nas aulas do Proeja atividades envolvendo a música:

Música é o meu lugar, onde tem música ali eu estou [...]. Sou movida a música.[...] Toda a minha família canta, nunca tivemos aula de canto, é um dom, já vem de criança. [... ] Pretendo me formar em música.[...] No primeiro dia de aula [...] percebi que aqui tem aula de música. Teve apresentação com flauta transversal e violino, depois violão e canto. Isso me alegrou mais ainda, pois descobri que a escola onde estudo já tem boa parte do meu futuro. (GEVAERD; KAWANO, 2006, p. 14)

Todo o processo de produção da obra (escrita dos textos, digitação, ilustração, layout final, papel e tinta para impressão) foi compartilhado pelas professoras e pelos alunos.

Buscando promover a circulação social dos textos produzidos na escola, no lançamento do livro foi realizada uma tarde de autógrafos, com a presença de professores, colegas e familiares dos alunos. A apresentação de um Pôster na Primeira Jornada da Produção Científica da Educação Profissional e Tecnológica de Santa Catarina, em 2007, nos campi do CEFET ${ }^{4}$ Florianópolis e São José possibilitou também a participação dos alunos num evento científico, outro importante resultado deste trabalho. Assim escrevem as professoras-autoras, no pôster do referido evento:

Essa atitude interdisciplinar promoveu a autoconfiança dos alunos, no que se refere à escrita; fez com que percebessem que produção textual não é atributo único das aulas de Português; demonstrou que não há barreiras entre as disciplinas; despertou maior interesse pela leitura e pela escrita; resultou na construção de uma imagem significativamente positiva em relação ao saber e à escola. Pensar na Educação de Jovens e Adultos

4. O atual Instituto Federal de Santa Catarina - IFSC - surgiu em 1909 como Escola de Aprendizes Artífices de Santa Catarina. Passando por várias mudanças de nome, transformou-se, em 2002, no Centro Federal de Educação Tecnológica de Santa Catarina (CEFET/SC) e em 2008, em Instituto Federal. 
é pensar em alternativas diferenciadas e até mesmo ousadas, no discurso e na prática, voltadas, sobretudo, para a interdisciplinaridade.

Essas produções aguardavam ser recuperadas e submetidas à análise, pois revelam muito do universo desses alunos jovens e adultos que chegam às salas de aula em espaços diversos - entre eles, os dos institutos federais.

O VENTO QUE VEM DE LONGE

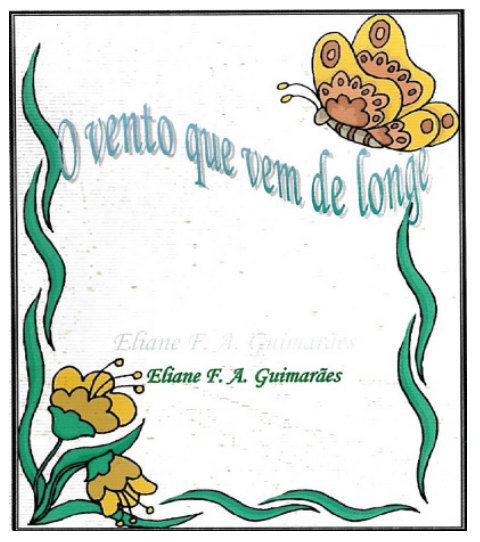

A obra de 38 páginas reúne 25 poemas de uma aluna inicialmente medrosa, caladinha, e tímida que aos poucos foi se revelando uma mulher forte, corajosa $[. .$.$] e ao mesmo tempo, uma alma obser-$ vadora, sensível, romântica, sonhadora, que produz incessantemente, convulsivamente. Seus poemas brotam a todo instante, diante de qualquer fato. (GUIMARÃES, 2006, p. 7)

Essa é a descrição da autora na apresentação da obra. Na escrita, revela-se toda a sensibilidade da autora-aluna, Eliane Guimarães, uma adulta que retorna à escola e que se sente deslocada, mas o deslocamento não a amedronta. Ao contrário, permite que ela reflita sobre a condição social que divide com tantos que também vivem o sentimento de exclusão da escola e dos conhecimentos por ela sistematizados. É o que vemos no poema "Temática da vida":

Que posso fazer

Se não entendo Física

Não compreendo Matemática

Em História resume-se minha vida.

A vida faz tanta Arte comigo

5. Este livro foi também organizado pela professora e impresso de forma praticamente artesanal, com recursos próprios e apoio do então CEFET, hoje IFSC, em março 2006. A imagem abaixo do título é da capa do livro. 
Que a ciência não explica mais a minha origem

Geografia me dá uma ideia

Do meu lugar no mundo.

$[\ldots]$

Com paciência e sorriso

Transformando meu mundo triste num grande paraíso

Esterzinha, minha solidez,

Minha querida professora de Português (GUIMARÃES, 2006, p. 17).

Percebe-se, ao longo do texto, o movimento que a aluna faz, ao se sentir atraída a revelar-se por meio da escrita. $\mathrm{O}$ estímulo da professora deu movimento à caneta, e a vida da estudante se faz ver em forma de versos. "Só quem a acompanhou de perto é capaz de revelar o que os versos des-velam," diz a professora de Português. Muitas histórias, que em cada página se entrelaçam e contam do cotidiano, como se dá no poema "Vinte e quatro horas":

Vinte e quatro horas sem energia elétrica

Faz diferença, meu amigo!

De repente, a minha vizinha da frente que nunca havia falado comigo,

Abre a janela e sorri para mim!...

Inicia um diálogo sob o pretexto da falta de luz, uma conversa

Que parecia não ter fim.

$[\ldots]$

Neste dia a vila se reuniu, as pessoas dialogaram.

A falta de luz iluminou as cabeças paradas! (GUIMARÃES, 2006, p. 30).

Para o leitor torna-se possível adentrar, em parte, no cotidiano da aluna, nas linhas e entrelinhas de alguns poemas que revelam o vivenciado e o vivido: a casa onde viveu feliz, acolhida por uma família, é registro vivo na memória da autora, inclusive o nome da rua, o número da casa, o sobrenome da família. Lembranças boas de professores marcantes, história de amor por um pai que nunca conheceu e outras tantas sem final feliz: 


\begin{abstract}
Alguém
Nos caminhos em que andei

Você não deve pisar...

Nos portos que ancorei

Você não vai embarcar...

Nos rios que cruzei

Você não vai navegar

Nas ondas que enfrentei

Você não vai deslizar...

As dores que aguentei

Você não vai suportar...

Nos tombos que eu levei

Você não vai acreditar...

Os mares que eu singrei

Você não conhecerá...

[...] (GUIMARÃES, 2006, p. 38).
\end{abstract}

Os poemas são portadores de elementos para análise e compreensão da história de vida da autora, também sendo parte dela revelada na entrevista ${ }^{6}$ feita com a professora. Neste revelar-se pela produção escrita de forma "incessante e convulsiva", no dizer da professora, escola e vida se misturam em diversas passagens, e a escola sobressai como espaço que nutre "a vida atribulada", pois os professores são "anjos que me incentivam", e os colegas são pessoas que me "alavancam" (GUIMARÃES, 2006, p. 35).

Para averiguar os desafios à prática docente, Aguiar Júnior (2010, p. 238-9) toma para análise em sua pesquisa dados provenientes de diversas fontes que lhe propiciam destacar e eleger cinco desafios que se apresentam às práticas de professores experientes e professores iniciantes. Como pondera o autor, "desafios cruciais para re-pensar a ação docente em sala de aula nos tempos atuais”. São eles:

1. Promover e sustentar engajamento dos estudantes nas tarefas escolares.

2. Re-significar conteúdos escolares.

3. Construir um currículo composto por atividades.

6. Entrevista gravada em 2015 pelas autoras deste artigo. 
4. Estabelecer interações discursivas produtivas, com participação dos estudantes.

5. Lidar com diversidade cultural, motivações, ritmos e habilidades dos estudantes. (AGUIAR JÚNIOR, 2010, p. 249)

Aguiar Júnior (2010, p. 240) identifica "a centralidade do primeiro desafio como sendo aquele que é mais recorrente nas falas dos docentes e que, de certo modo, se desdobra e condiciona os demais". Embora o autor esteja falando das licenciaturas em ciências de um modo geral, e o caso específico deste artigo sejam sujeitos da EJA/PROEJA, o que se pode perceber na prática submetida à análise é que a mediação feita pela professora nas atividades propostas aproxima-se muito do enfrentamento desses desafios.

VIVENDO E APRENDENDO COM A TURMA 132

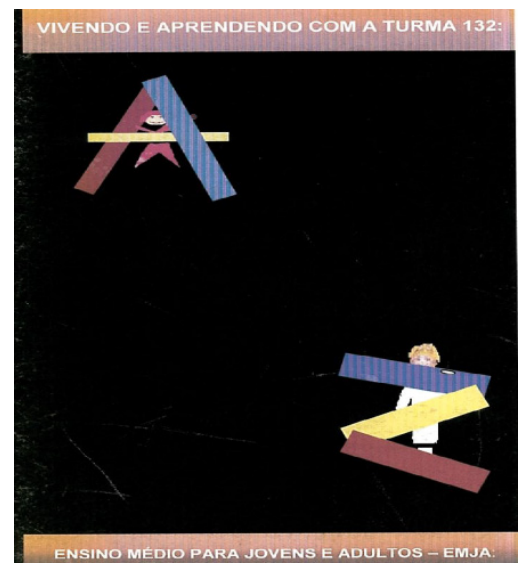

As formas de promover e sustentar o engajamento dos estudantes nas tarefas escolares aparecem sempre renovadas nas propostas de trabalho que originaram os livros em análise neste artigo. Ao dar voz aos 25 sujeitos-alunos que constituíam a Turma 132 no ano de 2008, elas nos revelam sobre a vida e sobre os sonhos de cada um. Na apresentação da obra, a professora aponta uma das estratégias usadas para levar os alunos a perceber o mundo da escrita que os cerca:

Como as mensagens verbais estão escritas por aí? Há preocupação de seus emissores em escrever corretamente as mensagens? Você seria capaz de identificar as incorreções 
e, após, corrigi-las? O desafio estava lançado. As correções de forma contextualizada deveriam ser apresentadas em um texto narrativo. (GEVAERD, 2008, s.p.)

Diferentemente do que ocorreu com as duas publicações anteriormente apresentadas neste artigo, a escrita desse livro não traz as experiências de vida dos sujeitos envolvidos na sua produção. Aqui, foi preciso muita mediação da professora organizadora para que os sujeitos se apropriassem de conhecimentos do mundo da literatura e das questões que envolvem a estrutura gramatical da língua portuguesa, para escrever sobre dois ilustres personagens brasileiros: o escritor Machado de Assis e o folclorista ilhéu e professor Franklin Cascaes.

O livro, organizado em estrutura de história em quadrinhos, começa com breves dados biográficos de Machado de Assis e Franklin Cascaes e também apresenta outros personagens da história, com algumas informações para melhor caracterizá-los: a Dúvida, a Certeza, o Dicionário e a Gramática. Os dois ilustres personagens, Machado de Assis e Franklin Cascaes se encontram (no céu, claro!) e começam a conversar sobre as dificuldades com o uso da língua portuguesa. Inicia-se um diálogo, destacando, nessa conversa, o jeito de falar e se comunicar das pessoas da Ilha de Florianópolis, herança dos imigrantes açorianos que fundaram as comunidades - um jeito cantado e corrido de falar, denominado de linguagem do "Manezinho", designa as características da fala de quem nasceu na Ilha.

A conversa entre os dois personagens vai se desenrolando em torno da língua falada e escrita, comentando alguns erros de grafia das palavras, os regionalismos e o folclore da Ilha. Algumas obras de Machado de Assis entram nessa conversa, conduzindo o leitor para a segunda parte da obra. Essa parte do livro trata especificamente da atividade proposta aos alunos, que é a de perceber a escrita que os cerca, selecionar mensagens escritas de forma incorreta e tentar corrigi-las. As cenas se passam com a conversa de duas personagens: a Dúvida e a Certeza. A Certeza apresentará à Dúvida o Senhor Dicionário, a Dona Gramática e a Regra. Por esse caminho da narrativa, vão sendo trabalhados o $x \operatorname{com}$ som de $z$, palavras com $s$ e c, pontuação, tudo voltado para fornecer à Dúvida algumas orientações de escrita.

As figuras seguintes dão uma ideia de como a produção foi sistematizada pelos alunos: 

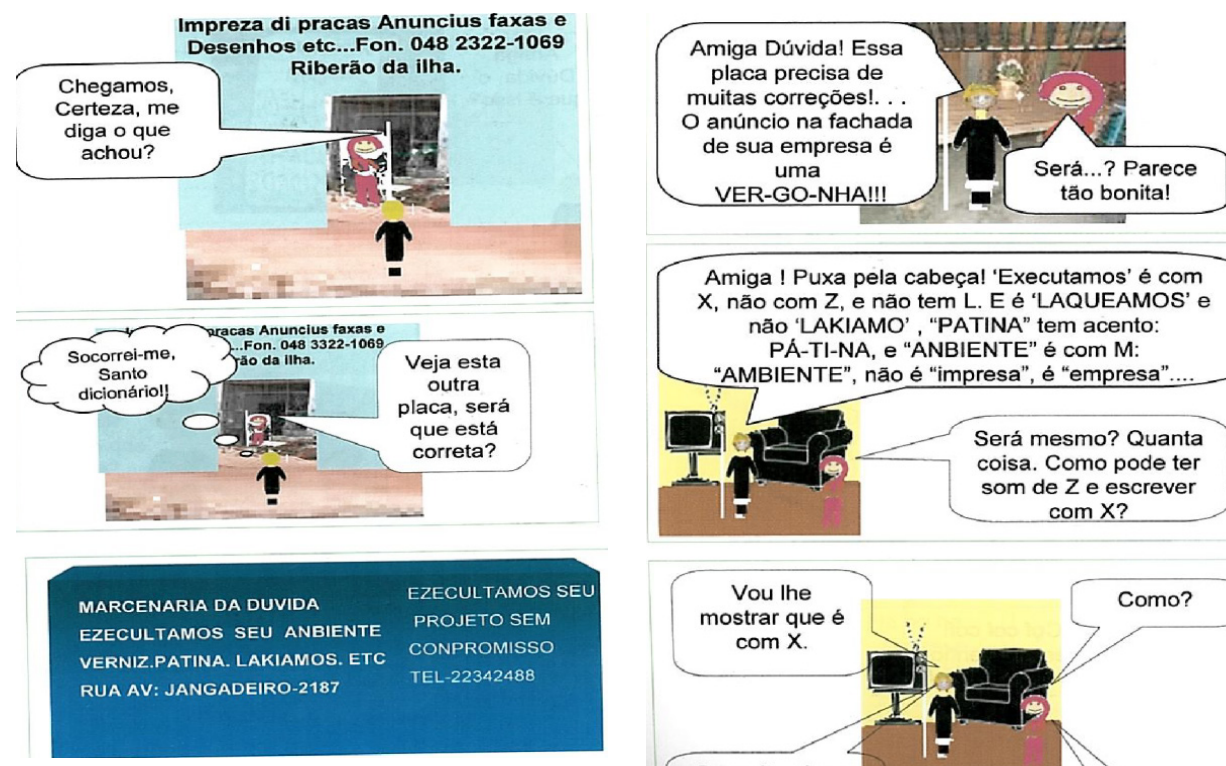
Amiga ! Puxa pela cabeça! 'Executamos' é com $X$, não com $Z$, e não tem L. E é 'LAQUEAMOS' e não 'LAKIAMO', "PATINA" tem acento: PA-TI-NA, e "ANBIENTE" é com M: AMBIENTE", não é "impresa", é "empresa"

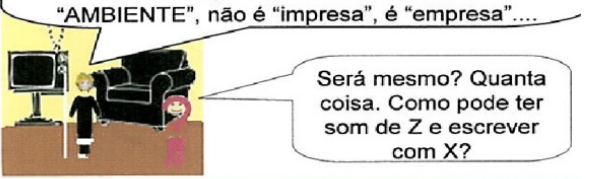

MARCENARIA DA DUVIDA

EZECULTAMOS SEU ANBIENTE

VERNIZ.PATINA. LAKIAMOS. ETC

RUA AV: JANGADEIRO-2187
CONPROMISSO

EL-22342488

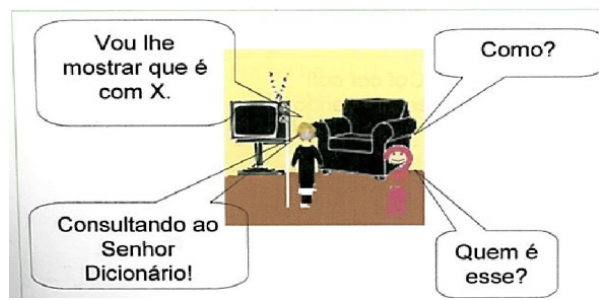

Fonte: GEVAERD, 2008, p. 21-22

Na proposta de trabalho, a professora, utilizando-se de recursos e estratégias diferenciadas, reinventa a prática, ressignifica conteúdos, ao problematizá-los e ao fazer os alunos pensarem sobre eles. Ela propõe o "engajamento disciplinar produtivo" dos estudantes. Eagle e Conant (apud AGUIARJÚNIOR, 2010) identificam quatro princípios para promover este engajamento: 1. problematizar o conteúdo; 2. conceder autoridade aos estudantes na solução do problema proposto; 3. comprometer os estudantes com os outros e com a tarefa; 4. prover os estudantes de recursos relevantes. Em todo o trabalho aqui analisado, vê-se que as propostas desenvolvidas pela professora foram fundamentais para estimular os alunos a realizá-las. 
PROEJA - O ALUNO ${ }^{7}$

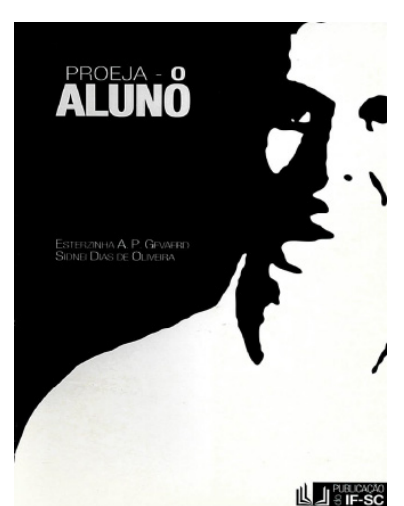

Diferente das experiências anteriores de produções de alunos do Proeja que viraram livro de forma artesanal, com investimentos dos próprios alunos e, especialmente, da professora organizadora, a publicação Proeja - o aluno contou com recursos públicos para editoração e impressão. Também foi o livro que teve mais repercussão, considerando a tiragem da publicação e a sua disponibilização em versão online $e^{8}$. livro de 92 páginas, publicado em 2009, traz a história de Sidnei, um aluno do Proeja que abraçou a proposta de trabalho feita pela professora para o desenvolvimento da escrita: a produção de histórias de vida, relatos pessoais ou experiências marcantes desses sujeitos. Ao se engajar na proposta, Sidnei passa sua vida a limpo.

A voz de Sidnei, inicialmente presa a sete chaves, só pôde ser ouvida depois de um intenso e cuidadoso trabalho de estabelecimento de vínculo, cultivado pacientemente pela professora. "Ele não havia se dado conta, mas a história estava lá, guardada na sua mente, prontinha para ser escrita, e digna de ser contada”, explica a professora, na apresentação do livro (GEVAERD; OLIVEIRA, 2009, p. 12). Da forma desconfiada com a qual inicialmente encarava as propostas de produção e as iniciativas de aproximação da professora para o trabalho de desenvolvimento da escrita, ao exercício do direito de dizer-se e saber-se, foi um longo caminho, revela a professora, em entrevista. Como indaga Arroyo (2014, p. 26): "Se os educandos

7. Este livro foi publicado pelo IFSC em 2009, em coautoria com a professora, pois esse era um pré-requisito para participar do edital de publicação de livros do IFSC. A imagem abaixo do título reproduz a capa do livro.

8. Disponível em: https://www.ifsc.edu.br/documents/30701/523474/Proeja_OAluno_web.pdf/4be5e3767707-co7e-1434-7d6c48d293f6. 
são Outros, a docência, os docentes poderão ser os mesmos?”. Outros sujeitos, outras pedagogias, é o que podemos dizer, quando refletimos sobre as propostas de produção escrita analisadas neste artigo.

É o autor-aluno exercendo o seu direito de dizer-se. É a oportunidade de "tirar as memórias dos Outros dos lugares periféricos” (ARROYO, 2011, p. 300). E continua insistindo Arroyo (2011, p. 265): "É esperar demais dos currículos, do conhecimento escolar e de seus mestres que o percurso escolar seja um avanço no direito a saber-se? Incorporar nos currículos suas memórias será uma oportunidade de entender-se". E é com esse entendimento de si que o aluno-autor se revela no livro. Ao longo de todo o texto, Sidnei partilha sua vida:

Hoje tenho um norte na vida. Ficou para trás aquele menino que foi gerado numa cela de penitenciária, que foi criado sem pai nem mãe, que parecia não ter futuro. Também ficou para trás aquele "aluno" cheio de dúvidas, de incertezas. Elas já não existem mais. Os estudos me ajudaram muito. Percebo mudanças em mim e creio que essas mudanças são visíveis por todos que me conhecem. O PROEJA fez de mim um ser humano melhor, na vida conjugal, paternal, social física e moral. (GEVAERD; OLIVEIRA, 2009, p. 69)

As experiências pessoais de um sujeito que retorna para a escola depois de adulto revelam o reconhecimento pelo papel desempenhado pela escola na vida do autor. "Sinto-me como uma pedra bruta, que durante três semestres foi lapidada pelas mãos de mestres, doutores da arte do saber. Sinto-me como ouro bruto que, ao ser jogado ao fogo, purifica-se, queima todas as impurezas e sai joia rara", descreve Sidnei (GEVAERD; OLIVEIRA, 2009, p. 69).

E ele faz referência ao aprendizado ao longo de cada disciplina, articulando-o à sua vida:

Sinto-me como um olho d'água, que jorra um fio deste valioso líquido e alimenta um Rio de Esperanças. Sinto-me como um pequeno olho do Saber, que jorra um fio de Matemática, Física, Química, Biologia, Informática, Português, História, Sociologia, Filosofia, Geografia, Artes, Inglês, Espanhol, Educação Física... Um fio destas valiosas disciplinas que alimentam um mundo de esperanças.

- A Matemática e a Física ajudaram-me no trabalho (Eletrônica).

- A História e a Geografia deram-me um Norte neste Planeta.

- A Biologia e Educação Física ensinaram-me a respeitar essa máquina humana que sou. 
- A Filosofia e a Sociologia deram-me um sentido na vida e para a vida.

- O Inglês e o Espanhol deram-me inclusão social.

- As Artes e a Informática tornaram-me culto e atualizado.

- A Química deu-me acesso ao Átomo.

- O Português me proporcionou o acesso a todas essas disciplinas.

Hoje, os princípios éticos e os valores morais fazem parte do meu cotidiano. (2009, p. 69-70).

Valeu a pena passar pela Selva do Saber,

Lutar contra o Leão da incerteza,

A Anaconda da dúvida,

O Crocodilo do desânimo,

O Elefante das dificuldades,

Atravessar o Rio do reforço,

Para chegar ao Éden do Conhecimento.

[...]

Vislumbro, em um futuro muito próximo, a seguinte situação:

- Como é o seu nome?

- Sidnei Dias de Oliveira.

- Idade?

-36 anos.

- Estado civil?

- Casado.

- Grau de escolaridade.

- Ensino médio completo.

- Sua Profissão?

- Sou Técnico em Eletrônica, formado pelo Instituto Federal de Educação, Ciência e Tecnologia de Santa Catarina.

Eu não me deixei levar pela vida. Segurei firmemente as rédeas do destino, tracei a rota e conduzi, eu mesmo, a minha vida. E VOCÊ? (GEVAERD; OLIVEIRA, 2009, p. 69-71, grifos no original).

A experiência de Sidney foi analisada em um artigo por Gevaerd e Viella (2012). As autoras discorrem sobre a importância de dar voz aos sujeitos da Educação de Jovens e Adultos, historicamente excluídos da escola: 
Com Um Toque de Criação: a mediação pedagógica na formação de leitores e...

Ao escrever sua história e se revelar nessa obra, o aluno deixa marcas em todas as páginas, da diferença que a escola fez na sua vida. Dos traços de dor diante das dificuldades sobressai também um grito de incentivo e de esperança, para tantos outros que como nosso autor, são jovens e adultos que estão alijados do processo formal de escolaridade e procuram a escola em busca de qualificação. Eles retornam à escola pela dificuldade em manter-se num mercado de trabalho competitivo, em que cresce a busca pela qualificação até mesmo nas atividades de baixa renda mensal, ou mesmo objetivando melhorias profissionais. Precisam, portanto, pelo menos cursar o Ensino Médio para poder desenvolver o seu potencial, melhor integrar-se no mercado de trabalho e, acima de tudo, exercer a sua cidadania. (GEVAERD; VIELLA, 2012, p. 447)

É Arroyo (2011, p. 264) que vai nos dando algumas chaves para melhor compreender "com que saberes saber-se", pois, segundo o autor, o direito a saber-se assegura acesso ao conhecimento, renova a forma de olhar e atuar com esses sujeitos na escola, reconhecendo que "carregam um saber-se produzido no seu viver" (p. 286).

Esses são os caminhos trilhados nas propostas apresentadas neste artigo. Elas revelam a possibilidade de construir outras práticas, abrindo espaços político-pedagógicos no território de tantas lutas dos currículos na Educação de Jovens e Adultos.

\section{CONSIDERAÇÕES FINAIS}

As pesquisas em Educação, muitas vezes, acabam por atribuir ao professor, especialmente aquele que atua na Educação Básica, um rol de competências que ele "precisa" possuir para se constituir como tal, definido na sua negatividade, a partir daquelas competências que não tem. Zeichner (1998, p. 210) afirma que uma das razões "para a falta de entusiasmo dos professores para a pesquisa acadêmica sobre a educação é a frequência com que eles se veem descritos de forma negativa”. Esse olhar sufoca outros traços que revelam o professor de corpo inteiro, na sua positividade, apontando outra face da docência.

Recolocar os professores no lugar de destaque que lhes cabe supõe superar imagens e autoimagens que foram se configurando história afora e volta e meia retornam. Será que os novos tempos impõem realmente novas imagens ou, como diz Arroyo (2000), as novas imagens mais nos enclausuram do que nos libertam? E continua o autor indagando: que imagens e autoimagens de mestre e de seu ofício estão em construção nas últimas décadas? 
Ao longo deste artigo, procurou-se apresentar experiências de escrita com sujeitos da Educação de Jovens e Adultos que permitiram evidenciar o lugar de destaque dos professores que, na pluralidade de ações significativas, silenciosas e transgressoras, vêm construindo em seu cotidiano práticas inovadoras. As ações aqui descritas são compreendidas não como meras atividades, mas como soluções para ocorrências imprevisíveis e que dependem, para seu enfrentamento, de conhecimento teórico. Conforme consideram Kuenzer, Abreu e Gomes (2007, p. 471):

[...] a prática por si não ensina, a não ser pela mediação da ação pedagógica. São os processos pedagógicos intencionais e sistematizados, portanto, que, mediando as relações entre teoria e prática, ensinarão a conhecer. Portanto, não basta inserir o trabalhador na prática para que ele espontaneamente aprenda.

A prática desenvolvida nas experiências aqui apresentadas explicitou as concepções teóricas que sustentam a ação docente, servindo de referência para um ensino de língua materna que valoriza o aluno na condição de autor de textos com efetivo valor social. Ainda, a socialização dessas atividades, via este texto que ora finalizamos, revelou estratégias de trabalho possíveis de serem desenvolvidas em outros espaços formativos. Sobretudo, em espaços que têm como sujeitos os alunos da EJA, com tantas histórias de vida a partilhar.

\section{REFERÊNCIAS}

AGUIARJÚNIOR, O. A ação do professor em sala de aula identificando desafios contemporâneos à prática docente. In: DALBEN, Â. et al. Convergências e tensões no campo da formação e do trabalho docente: Educação ambiental, educação em Ciências, educação em espaços não escolares, Educação Matemática. Belo Horizonte: Autêntica, 2010. p. 238-264

ARROYO, M. G. Ofício de mestre: imagens e auto-imagens. Petrópolis, RJ: Vozes, 2000.

ARROYO, M. G. Currículo, território em disputa. 2. ed. Petrópolis, RJ: Vozes, 2011.

ARROYO, M. G. Outros sujeitos, outras pedagogias. 2. ed. Petrópolis, RJ: Vozes, 2014.

BRASIL. Decreto $N^{o} 5.478$, de 24 de junho de 2005. Institui, no âmbito das instituições federais de educação tecnológica, o Programa de Integração da Educação Profissional ao Ensino Médio na Modalidade de Educação de Jovens e Adultos - PROEJA. Brasília, 24 de junho de 2005.

FARIA, D.; ASSIS, S. O PROEJA integrado à Educação Profissional: desafios, possibilidades e práticas docentes. Holos, ano 30, v. 02, 2014. Disponível em: http://www2.ifrn.edu.br/ojs/index. php/HOLOS/article/download/1968/809. Acesso em: 11 jan. 2018. 
Com Um Toque de Criação: a mediação pedagógica na formação de leitores e...

GEVAERD, E. A. P. Vivendo e aprendendo com a turma 132-EMJA (Ensino médio para Jovens e Adultos). Florianópolis: Centro Federal de Educação Tecnológica de Santa Catarina-CEFET-SC, 2008.

GEVAERD, E. A. P.; KAWANO, M. Um toque de criação. Florianópolis: Centro Federal de Educação Tecnológica de Santa Catarina-CEFET-SC, 2006.

GEVAERD, E. A. P.; OLIVEIRA, S. D. PROEJA - O aluno. Florianópolis: IFSC, 2009.

GEVAERD, E. A. P.; VIELLA, M. A. L. PROEJA? Que história é esta? Revista Pedagógica Unochapecó, ano 15, v. 01, n. 28, p. 439-467, jan./jun. 2012.

GUIMARÃES, E. F. A. O vento que vem de longe. Florianópolis: Centro Federal de Educação Tecnológica de Santa Catarina-CEFET, 2006.

KUENZER, A.; ABREU, C. B. de M.; GOMES, C. M. A. A articulação entre conhecimento tácito e inovação tecnológica: a função mediadora da educação. Revista Brasileira de Educação, v. 12, n. 36, p. 462-549, set./dez. 2007.

OLIVEIRA, M. K. Jovens e adultos como sujeitos de conhecimento e aprendizagem. Revista Brasileira de Educação, n. 12, set./out./nov./dez. 1999.

RAMOS, E. E. L.; BREZINSKI, M. A. S. Legislação educacional. 2. ed. Florianópolis: IFSC, 2014.

ZEICHNER, K. M. Para além da divisão entre professor-pesquisador e pesquisador acadêmico. In: GERALDI, C.; FIORENTINI, D.; PEREIRA, E. M. A. (Org.). Cartografias do trabalho docente: professor(a)-pesquisador(a). Campinas, SP: Mercado de Letras; Associação de Leitura do Brasil-ALB, 1998.

\section{SOBRE AS AUTORAS}

Maria dos Anjos Lopes Viella é graduada em Pedagogia (Universidade Federal de Viçosa- MG), tem Mestrado em Educação (Universidade Federal de Minas Gerais) e Doutorado em Educação (Universidade Federal da Santa Catarina). É professora/pesquisadora aposentada do Instituto Federal de Educação, Ciência e Tecnologia de Santa Catarina. Tem experiência na área de Educação, com ênfase em Educação e Trabalho, Ensino e Formação de Professores, pesquisando os seguintes temas: Mundo do trabalho, juventude e escola, pesquisa e formação de professores e formação de professores para a Educação Profissional e Tecnológica. E-mail:mariadosanjosv@gmail.com.

Marizete Bortolanza Spessatto é graduada em Pedagogia (Fundação de Desenvolvimento do Oeste), tem Mestrado em Linguística (Universidade Federal de Santa Catarina) e Doutorado em Educação (Universidade Federal de Santa Catarina). É professora/pesquisadora do Instituto Federal de Educação, Ciência e Tecnologia de Santa Catarina. Tem experiência na área de Formação de 
Leitores e Formação de Formadores, com pesquisa nos seguintes temas: formação de professores, formação de leitores, formação de professores em Educação Profissional e Tecnológica, políticas públicas.

E-mail: spessatto.mari@gmail.com.

Recebido em 29 de maio de 2019 e aprovado em 26 de julho de 2020 